\title{
BoP and MNCs: Where is the Market and Where the Source of Innovation?
}

\section{Dr. Marcello Tonelli}

Australian Centre of Entrepreneurship Research (ACE) Business School, Queensland University of Technology GPO Box 2434 Brisbane 4001, Australia m.tonell@qut.edu.au

\section{Nicolò Fabrizio Cristoni}

Master MaGER (Master in Green Management, Energy and CSR) Bocconi University, Sarfatti Street 25, Milan 20136, Italy nicolo.cristoni@master.unibocconi.it

Doi:10.5901/ajis.2013.v2n8p184

\section{Abstract}

In 2004 Prahalad made managers aware of the great economic opportunity that the population at the BoP (Base of the Pyramid) could represent for business in the form of new potential consumers. However, MNCs (Multi-National Corporations) have continued to fail in penetrating low income markets, arguably because applied strategies are often the same adopted at the top of the pyramid. Even in those few cases where products get re-envisioned, their introduction in contexts of extreme poverty only induces new needs and develops new dependencies. At best, the rearrangement of business models by MNCs has meant the realization of CSR (Corporate Social Responsibility) schemes that have validity from a marketing perspective, but still lack the crucial element of social embeddedness (London \& Hart, 2004). Today the challenge is to reach the lowest population tier with reinvented business models based on principles of value co-creation. Starting from a view of the potential consumer at the BoP as a ring of continuity in the value chain process - a resource that can itself produce value - this paper concludes proposing an alternative innovative approach to operate in developing markets that overturns the roles of MNCs and the BoP. The proposed perspective of 'reversed' source of innovation and primary target market builds on two fundamental tenets: traditional knowledge is rich and greatly unexploited, and markets at the top of the pyramid are saturated with unnecessary products / practices that have lost contact with the natural environment.

Keywords: Base of the pyramid, grassroots innovation, inclusive development, poverty alleviation, traditional knowledge.

\section{1. introduction}

The BoP can no longer represent for MNCs just the new market opportunity identified by Prahalad in 2004. The emphasis of their international business development strategies cannot be based on making a profit by selling products and services to 4 billions of poor people; the concept of 'selling to the poor' needs to be replaced with a new terminology aimed at solving together the great challenges of the world, among which is poverty. Open business models (Howe, 2008), requalification of the consumer as prosumer (Toffler, 1980), strategies to co-create (Hart \& Sharma, 2004), appreciation of traditional knowledge (Seyfang \& Smith, 2007) are some of the concepts discussed in this paper.

One of the primary causes of the failure by MNCs in penetrating the BoP is considering the poor as regular consumers, representing the last link of the economic value chain only devoted to destroy value. It is only recently that MNCs have started to recognize the potential of the BoP in terms of its innovative power. Another reason for the difficulty of MNCs in gaining a positive presence in developing countries is the incorrect or insignificant implementation of CSR strategies (Davidson, 2009), too often used as a 'mask' for conscious consumers and to gain access in BoP markets. But the use of CSR to somehow justify business wrongdoing in the eyes of society is just a temporary patch as information travels fast in today's world and consumers are growing more and more alert (Hart \& Sharma, 2004). Also, CSR as a marketing strategy carries only short-term rewards that are often not worth the time and resources invested.

Those organizations that seek to successfully enter the BoP can do so if they acknowledge the latent potential of the people in those settings and learn to co-operate with other stakeholders in order to achieve sustainable development. Furthermore, there is growing evidence that the BoP might contain precious knowledge, lost by the western world, that could solve global challenges and set human development on a new course. 


\section{The Failure of MNCs in Penetrating the BoP}

In 2004 Prahalad found a new market opportunity at the BoP. He suggested the idea that 4 billions of poor people have immense business capacity and purchasing power, though individually limited. They represent, therefore, a market that still has to be conquered. Since markets at the top of the pyramid are characterized by ever-shorter product life cycles and almost completely satisfied needs, the Indian economist urged MNCs to turn their efforts toward the BoP. However Prahalad did not go beyond the concept of 'selling to the poor', considering poor people only as new potential consumers able to absorb the supply of MNC products.

As a result, MNCs have repeatedly tried to penetrate the BoP on a market-based strategy, backed up by the belief that "market-based approaches offer an attractive alternative [to donation-based aid programs], as they can be economically sustainable" (London 2008, p. 6); they help fostering a 'participated" economic growth that can arguably alleviate poverty in the world. Despite such hope, Monitor Group (2011) demonstrated that unfortunately most MNCs fail because they try to penetrate the BoP without rearranging their business models. Why don't MNCs define business models appropriate for new markets at the BoP? This is primarily due to two factors. The first is linked to the company itself: business model rearrangement is a very complex and expensive process requiring innovation and changes at the organizational culture level. The second set of causes relates to what companies think about the BoP: it is not worth enough to make organizational changes; it does not have a great purchasing power; it is hard to reach due to wide media-dark areas and a weak infrastructure; people do not have clear needs.

The practical consequences of such activity over the last decade are that MNCs still try to sell products to the poor that people at the top of the pyramid no longer want; consumers at the BoP do not appreciate or find useful the newly introduced products because, in most cases, are not fitting their basic needs; and the corporate involvement at the BoP gets reduced at best to CSR exercises to strengthen reputation in the eyes of the Western world.

When Nike launched its World Shoe program in 1998 with the scope of penetrating low-income markets, it pursued a new business model. Local-for-local manufacturing, concurrent engineering product development approach and market classifications had been envisioned as the three main pillars of the market entry strategy. However, as the company failed to understand that selling to the poor requires complex interaction, empathy (Hart \& Sharma, 2004) and a deep understanding of local needs, culture and habits, so did its business plan. Nike's misstep provides the insight that unless businesses are locally embedded in the targeted region, plans for conquering new markets in developing countries are bound to fail in the long run (Simanis \& Hart, 2008). Accordingly, business models need to be re-shaped in light of the urgencies of the communities at the BoP, specifically by focusing efforts on satisfying unmet needs instead of creating new ones.

The Reuters Market Light (RML) project, as an example, found its success by providing Indian farmers with a customized information service aimed at improving their yields. RML follows the simple idea of providing rural farmers with a comprehensive set of information, from crops market price and weather forecast, to crop advisory tips and commodity news. SMS messages are received by subscribers in English or the language of their choice on a daily basis. The scope of the service is to enhance farmers' ability to negotiate with buyers and to enable them to arbitrage better across sales outlets. Furthermore, weather forecasts allows them to reduce crop losses due to unforeseen storms. Crop advisory information, finally, has the scope of letting farmers develop better cultivation practices and to push them in making timely decisions to adopt new crop varieties when needed (Fafchamps \& Minten, 2012). In India, a country with 127 million cultivators (60\% of the total population) devoted to crops' cultivation either directly or indirectly ${ }^{1}$, where agriculture contributes to $20 \%$ of GDP, the penetration of RML represents a unique opportunity to enable farmers to operate more efficiently while minimizing uncertainty.

When approaching consumers at the BoP, companies must realize that value creation is the key. Usefulness and affordability are the drivers that will eventually mark the line between success and failure. The Swiss-based healthcare technologies company Vestergaard Frandsen, provides products that embody both characteristics of being useful and relatively low-priced. The company pursues a "profit for a purpose approach" by delivering innovative emergency response and disease control devices in the most disadvantaged regions of the planet at affordable prices. Its products, ranging from a mosquito net that releases anti-malaria insecticides in the air to portable water filters, have been successful by virtue of the fact that the company operates at the core of the communities it serves. A consequence of this

${ }^{1}$ ICRIER, (2009). "India: The impact of mobile phones" (The Policy Paper Series, Number 9). Retrieved May 02, 2013, from http://www.icrier.org/pdf/public_policy19jan09.pdf 
approach is simple: urgent needs are readily identified and promptly satisfied. By placing laboratories in Cote d'Ivoire and Vietnam and centres of production in China, India, Korea, Thailand and Vietnam, Vestergaard Frandsen can match its local embeddedness with the capability to perform fast responses to humanitarian emergencies and disease outbreaks in many parts of the world.

\section{CSR To Mask Common Practices}

Corporate Social Responsibility (CSR) has definitely contributed to change the practice of MNCs. Over the last decades, MNCs have been increasingly forced to modify their behavior towards stakeholders, largely because of the major changes occurring in the environment they used to operate. Firstly, the number of NGOs monitoring MNCs practices especially in third world countries has increased dramatically during the last ten years (Hart \& Sharma, 2004). Additionally, the spread of the Internet and the explosion of social media have contributed to make consumers more informed and aware of MNCs unethical practices. Millions of people are now able to access information live and can communicate with each other instantly, thereby creating a global network of 'conscious consumers'. As a result of such major changes, large corporations have been exposed to public opinion in a way that is nearly impossible for them to behave unethically without ending up under the attack of some NGO, consumer association or an individual blogger.

According to this logic, several industries are undergoing important transformations. Some of the largest pharmaceutical companies ${ }^{2}$, for instance, have lately implemented more socially sound business models setting drug prices based on a country's population ability to pay. This has resulted in price dropping in developing countries up to $90 \%$ (Gottlieb, 2000). After having repeatedly been accused of operating detached from society, the pharma business has now come to realize that in order to sustain long-term success, expectations from a growing body of conscious citizens have to be met. Similarly, when in April 2008 Greenpeace International publicly condemned Unilever by releasing a report entitled: "How Unilever palm oil suppliers are burning up Borneo" it became clear to the company that a new stakeholders-oriented strategy had to be pursued or the report would have jeopardized the reputation of Unilever worldwide. Therefore, on $1^{\text {st }}$ May 2008 Unilever announced its commitment to import only Certified Sustainable Palm Oil by 2015 and launched a partnership with WWF to halt further deforestation.

In other words, it is reasonable to say that CSR has emerged amongst MNCs as the new frontier for reconciliation with the global community. International companies seeking to protect their corporate image against human rights scandals, environmental catastrophes and unveiled corruption practices have found the way to 'greenwash' their brands by committing themselves to CSR behaviors and transparency.

However, CSR practices at the BoP have generally been limited to projects unable to have a substantial, long-term impact (Davidson, 2009). At best, companies' commitment has resulted in projects sponsoring social initiatives or the delivery of low-cost services to underdeveloped regions in Africa, South-America or Asia. As a result, CSR often appears to be no more than a marketing tool, a 'mask' that MNCs can wear to appear ethical.

In fact, when CSR initiatives approach the poor distributing them products or services at apparently convenient terms, negotiations still follow the traditional market notions, according to which companies are autonomous in the design and manufacture of goods/services and customers are just users (Prahalad \& Ramaswamy, 2004). This is a typical firmcentric view of the market, which considers consumers as the last link of the value creation process and dedicated only to consumption. The two sides of the economic equation - producer and consumer - remain distinct and the only connection between them are activities such as customer satisfaction and customer relationship management, none of which however allow consumers to actively participate in the production process. Therefore, the vast majority of implemented CSR initiatives do not seem sufficient to satisfy the needs at the BoP because they continue to create value just for MNCs and not for the communities they serve.

\section{MNCs Recognize the Potential of the BoP to Innovate and Co-Create}

The obvious consequences of adopting a standard transnational business model (Bartlett \& Goshal, 1989) at the BoP are the creation of new needs amongst the poor, the introduction of hardly sustainable products in markets not ready to accept them (largely because of missing specific infrastructure), and the encouragement of new habits far from ordinary life. Keeping the distance between who creates value and who consumes it, the transnational model excludes the 
possibility that the BoP could create value.

On the other hand, the co-creation model (Prahalad \& Ramaswami, 2000) lies on the principle that companies can harness their customers competences by engaging with them and move beyond the mere buyer-seller relationship. Thus, on the basis of this new set of co-creation experiences (Prahalad \& Ramaswami, 2004) the interaction between the company and the client becomes itself the locus where the value creation process finds its climax.

Examples of co-creation in mature markets are growing and spreading over the entire spectrum of industries. Take Amazon. Since its inception, the online book-seller business model has relied heavily on readers' feedbacks and reviews, encouraging the customers network to thrive and share information about books. Or take FIAT, the Italian automaker. Prior to taking the final decision about the design of its new Punto car, the company invited potential customers to visit the website and choose amongst different features and options. By doing so, the firm was able to test different designs at a negligible cost ending up with a vehicle that was way more inclusive of customers' preferences. Future clients, on their part, had the chance to shape the model according to their wants and needs.

Companies operating in mature markets pursue the co-creation approach in order to gain competitive advantage and build a long-term customer relationship. Similarly, we suggest that analogous strategies could apply to the BoP. Indeed, forms of co-creation are emerging even in the poorest parts of the globe. In more than 50 countries, the Sawa World project ${ }^{3}$ seeks to eradicate poverty by training young generations of journalists to document local agricultural best practices and then sharing them via a global network. Essentially, short videos about bold solutions are reported, regularly updated, and presented to nearby communities by the 'Sawa Youth Reporters'. By doing so, rural populations are encouraged to implement, adapt and upgrade innovative techniques: co-creation processes thus thrive amongst diverse neighbourhoods and in different locations simultaneously.

There is growing evidence that MNCs are beginning to recognize the potential value of consumers at the BoP to more effectively penetrate those markets (Simanis \& Hart, 2006). As highlighted by Hart and Sharma (2004) 'fringe' stakeholders - those who lie at the periphery of a company's network - can indeed become a source of innovation, provided that they are enabled to raise their voices and express their ideas. For them to do so, companies must therefore focus their efforts on building a network able to engage with these groups. Thus, Hart and Sharma propose a new approach of stakeholder integration, which "moves beyond the static management of known parties in the center of a network to the dynamic process of identifying and engaging actors from the fringe" (Hart \& Sharma, 2004:9). In light of this assumption, the BoP assumes the new role of a business partner instead of being considered just a passive body of consumers.

In evaluating alternative innovation-driven business models there seems to be an emergent trend towards open systems (Brabham, 2008; Howe, 2008) that promote dialogue among the various stakeholders involved and contemplate different provisions from each actor. As depicted in figure 1, economic and social transformation can result from the interactions of native people who bring know-how and traditions, BoP entrepreneurs who contribute with their drive to grow, MNCs which supply processes, technology, and resources, aid and development agencies that provide cultural mediating skills, government bodies that set laws and regulations, and BoP consumers who are given a voice. 
Figure 1. Different Roles for Different Stakeholders

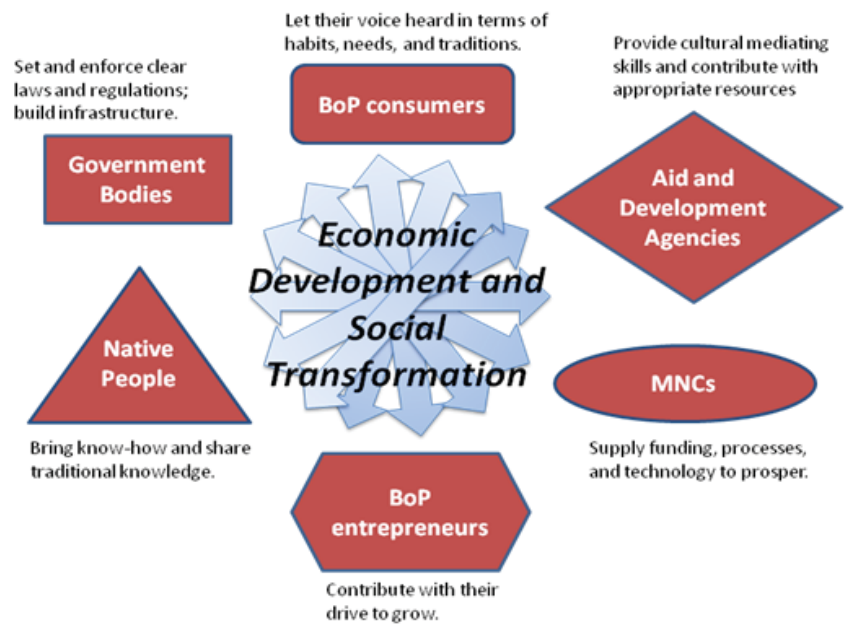

This indication of a possible alternative way of conducting business operations is in line with what was proposed by the World Business Council for Sustainable Development in 2001: a joint growth between MNCs, governments and civil society in order to sustain social development. In this regard, the United Nations had also launched in 2000 a robust campaign to involve the business world in the practice of sustainable development and poverty alleviation. The Global Compact program aims in fact to establish global 'sustainable development partnerships' between the UN, governments, civil society, labor, and business to promote the achievement of the MDGs (Millennium Development Goals). However the results still appear controversial as being a member of the program has not yet proven to be a guarantee of effective CSR management (Ecovadis, 2012).

When interactions among stakeholders work, the results can be really promising in setting a path that will eventually lead to the elimination of challenges that have for centuries plagued most of the southern hemisphere. In this regard, the Lighting a Billion Lives ( $L a B L)$ project provides a clear understanding of the magnitude of the potential benefits deriving from an open-system approach. Launched in 2008 by The Energy and Research Institute (TERI) and the Indian Government with the aim of bringing clean light and socio-economic development to remote un-electrified villages in India, the initiative is based on a localized, bottom-up entrepreneurial model. Essentially, local social entrepreneurs are trained to run small enterprises within the context of their villages offering the rent of high-quality solar lamps to rural people for an affordable fee. In order for the project to have effective, large-scale impact (1 million rural Indians was the original target) promoters envisioned a 5P's plan of action: 'pro-poor public-private partnership'. Embracing both, purely commercial and social welfare approaches (UNESCAP, 2010), the 5P's main scope is to encourage community participation and education and the generation of income for social development. To this end, not only governments and the private sector are involved but also NGOs, development banks, philanthropic institutions, community-based organizations and even private citizens are called to give their contribution to the success of the project.

Thus, in this new form of inclusive partnership, the 'pro-poor element' has been added to the usual public-private relationship. By enabling the poor to play the double role of end consumers and business partners, this pioneering business model intends to move beyond the traditional public-private partnerships (PPP), which have often ignored the needs of those at the BoP (UNESCAP, 2010). Accordingly, LaBL's pro-poor commitment pursues the main objective of effectively empowering and engaging with rural communities through a 5-stage process. As illustrated in Figure 2, communities are first approached to evaluate project's acceptance and to forge it according to local needs and requirements. Subsequently, an intensive in-loco training program is provided to the selected entrepreneur on both technical and economic aspects of the solar enterprise. The third stage is focused on the engagement of second level users and aims at making them aware of their consumers' rights and of the proper usage of lamps by a next-door aftersales support. TERI then harnesses feedback from the populations it serves so as to continuously ameliorate the design and the functionality of its service. Finally, the project aligns with other social programmes to bring training to the BoP on other income generation activities such as tailoring and selling mobile services (Chaurey, Krithika, Palit, Rakesh \& 
Sovacool, 2012). Thus far, the implementation of LaBL 5P's framework has proven successful. Major benefits for the poor have been attained by virtue of a well-orchestrated mechanism. Governments commitment to financially support the inception of the program has proceeded hand in hand with the willingness of the private sector to devote technological knowledge and business skills to a new typology of customers. Concurrently, non-profit and community based organizations have played the fundamental role of bridging the gap with rural communities by involving them in the cocreation and development of the project.

Figure 2. LaBL's 5-stage process

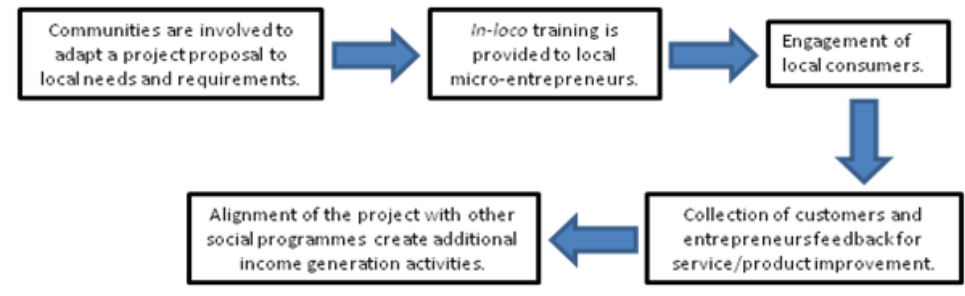

This is clearly a successful case, but not all scenarios are the same. When the process is manipulated by corruption, lobbying, short-term goals, and unethical business conduct aimed solely at profit maximization, then the consequences can be devastating. The African Agriculture Growth Corridors project, as an example, whilst being acclaimed by its sponsors and the media as the way to tackle food security concerns and poverty, raises a series of questions on why local communities have not been consulted over its implementation. The idea of African Agricultural Growth Corridors was envisioned to speed up the process of converting millions of hectares of land in the African continent to industrial agriculture use. Originally presented at the UN General Assembly in 2008, the project, endorsed by the World Economic Forum as a part of the broader "New vision for Agriculture" strategy, claims the transition to industrial agricultural practices in Africa will boost economic growth in the continent thereby lifting targeted regions out of poverty. In the words of the key sponsor of the project, the agribusiness multinational Yara International: "by connecting these areas to infrastructure, efficient logistics providing inputs, storage and transportation to markets, the goal is to forge viable value chains supporting both large-scale and smallholder farming ${ }^{4 \prime}$.

But to what extent smallholder farming will benefit from the development of the agricultural corridors? Land grabs, impoverishment and vast displacement due to the shift to industrial agriculture are amongst the many troubles farmers will likely have to face. Local communities and farmers associations (e.g. the International Peasants Movement) complain the massive project is being implemented with no previous public debate, especially with smallholders. Local knowledge, land management, habits and culture are not only being left out of the conversations, but are also jeopardized by the advent of western agricultural systems. By narrowly directing their attention to old mainstream stakeholders management practices, agribusiness companies have made no efforts to engage with local communities and to get the best out of the native knowledge.

\section{Innovation at the BoP May Hold the Key to Global Challenges}

Low tech, grassroots-level innovations (GRI) may hold the key to overcoming some of the resource challenges we face today. Over the last decades, the concept of 'sustainable development' has gained increasing importance and popularity as the challenges posed by climate change, resource and food scarcity, environmental degradation and biodiversity loss have become tangible threats for humanity. Within the nascent field of sustainable innovation studies, attention has been raised on the magnitude required for innovative ideas and practices to overcome sustainability challenges. Indeed, in order to radically revolutionize modern consumption habits and lifestyles, changes with systemic impact are needed (Hargreaves, Longhurst \& Seyfang, 2013). In light of this assumption, a variety of innovations have recently been the promoters of sustainability trends, both technological (the spreading of renewable technologies) and social (ethical

4 Yara International (2013). Agricultural Growth Corridors. Retrieved June 05, 2013, from http://www.yara.com/sustainability/ how_we_engage/africa_engagement/growth_corridors/index.aspx 
consumers movements). However, very few of these new developments have been capable of having repercussions on a global scale.

In this regard, a recent body of literature known as 'sustainability transitions' (Hargreaves, Longhurst \& Seyfang, 2013; Seyfang \& Smith, 2007; Smith, 2007) has tried to investigate and explain the circumstances under which green technological innovation are best able to thrive and to break up the paradigms of the existing system. Building on these efforts, the focus has then shifted to linking sustainable development with innovation at "grassroots level" (Seyfang \& Longhurst, 2012; Seyfang \& Haxeltine, 2012). Although GRI might not possess enough power to drive society into a more sustainable future, it has nonetheless begun to be considered a valuable source of innovative diversity. Seyfang \& Smith (2007) argue that civil society initiatives, whilst differing greatly from mainstream business-driven transformations, hide a latent and under-estimated potential. Given their local embeddedness, community-driven innovations possess the knowledge, experience and capabilities to succeed where top-down, incremental and path dependent reforms have failed.

Researchers (Seyfang \& Smith, 2007) have pointed at "experimental niches" as the locus where disruptive, environmentally friendly innovations have historically originated. The term refers to networks of organizations, technologies and users that operate at the fringe of the system forming an alternative (i.e., niche) practice. Niche situations have proven successful in providing a "comfort zone" for new alternative insights and green practices to arise faraway from the regime's net of constraints and pressures (Smith, 2007). In other words, niches offer a safe operating space where actors can experiment sustainable technologies and processes without being curbed by limitations conventionally imposed by society.

Thus far this intriguing body of literature has focused solely on innovation led by individuals and organizations in developed countries, but little is known about innovation driven by BoP actors. In this article we argue that what has been to date discovered about bottom-up innovation and niche development in the western world could find rewarding application also in the context of the BoP. The concept of sustainable development has arisen in response to a wide range of unsustainable practices evolved in the 'developed' side of the globe. Being at the margin of the industrialized system, we maintain that underdeveloped countries offer the right conditions where fruitful, sustainable ideas can spring. Further, the motivations behind the efforts toward innovative solutions would appear to be even more robust with respect to individuals and communities at the BoP. Smith (2007) points at the will to meet social needs and the commitment to embody the "green ideology" as the major drivers for sustainability in grassroots level communities, though no distinction has been made between communities in western countries and those acting at the BoP. When it comes to the main drivers of sustainable innovation, indeed, the differences between the two contexts might be significant. In the two cases of GRI that will follow, for instance, what led farmers to experiment novel ideas was the urgency to face poverty, hunger and extreme climate conditions. In such contexts, local knowledge has been leveraged by the community as the only means to achieve better living conditions.

The two recent cases were chosen because they brought to light the immense potential of indigenous knowledge, thus attracting the attention of the global community. The protagonists of this stories, smallholders in Burkina Faso and India, have innovated the way cultivation had been traditionally conducted for centuries in order to face drought and famine. The outcomes achieved, however, have gone far beyond anyone's expectations.

The Method Zai, an innovative tree-farming approach, owes its success to the pioneering creative insight of Mr. Yacouba Sawadogo ${ }^{5}$, a smallholder living in the remote village of Goura, Burkina Faso. Located in the semi-arid Sahel Belt and bordering the Sahara desert to the north and the Sudanian Savannas to the south, the Yatenga region suffers from periodical rainless periods. After the massive drought of the 1980s, the rapid desertification of the once fertile plains forced the majority of the local population to migrate in search of more productive lands. Though, rather than abandoning his family-owned piece of land, Mr. Sawadogo brought to new light an ancient farming method local farmers had utilized for centuries, adapting it to the new climate conditions he had to face. Prior to Mr. Sawadogo's adaptation, Sahelian farmers had in fact long practiced the technique to dig holes (zai in the local language) so as to concentrate rainfall onto the roots of crops. Sawadogo's insight consisted of making larger pits in order to capture more rainfall and adding manure to the zai during the dry season. As a result, tree seeds in the manure germinated amid his rows of millet and sorghum thereby increasing soil fertility (by retaining moisture) and shielding crops from overwhelming heat and wind. Over a period of more than two decades, Mr. Sawadogo's efforts allowed him to create a forested area of approximately fifty acres. Technically known as "agro-forestry" or "farmer managed natural regeneration" (FMNR), the innovation has

\footnotetext{
${ }^{5}$ Yacouba Sawadogo is the subject of a documentary feature film 'The Man Who Stopped the Desert' made by 1080 Films.
} 
already been spread in vast portions of Burkina Faso and neighbouring Niger and Mali. Remarkably, according to The Nation: "The transformation has been so pervasive that the new greenery is visible from outer space via satellite pictures" (Hertsgaard, 2009). Local farmers are thus succeeding where government agencies, NGOs and development-project planners have always failed: winning the fight against desertification.

Bottom-up innovation is often triggered by desperate living conditions. Mr. Sawadogo's achievement has to do with his unwillingness to surrender to the desertification of his land and be forced to leave his country. Therefore, when it comes to fighting massive challenges such as poverty, drought and famine GRI might not surprisingly hold the key to success. In India, the spreading of an organic, fully sustainable and ultra-productive crop cultivation method developed by farmers at the BoP for example, promises to dramatically increment rural farmers yields whilst, at the same time, offering a concrete solution to the feeding of a fast-growing world population. Originally devised in the early 80's by the French Jesuit and agronomist engineer Henri de Laulanie in tandem with Malagasy farmers, the System of Rice Intensification (SRI) was brought to Asia in later 1990s by Norman Uphoff, an American scientist and professor. After a slow beginning that lasted more than 20 years, the outcome of the implementation of this alternative farming now seems miraculous. Since 2001, the Darveshpura village in the Nalanda district has been renamed "the miracles village": yield production world records are being broken one after the other in this remote village of one of the Indian's poorest states. In the beginning was just about rice, with an outstanding result of 22.4 tonnes of rice produced on one hectare of land attained by the local hero Mr. Sumant Kumar. Few months later, similar astonishing yield performances had been achieved by potatoes and wheat growers. The reason for that impressive outcome is SRI which, as described by The Guardian, consists in: "instead of planting three-week-old rice seedlings in clumps of three or four in waterlogged fields, as rice farmers around the world traditionally do, the Darveshpura farmers carefully nurture only half as many seeds, and then transplant the young plants into fields, one by one, when much younger. Additionally, they space them at $25 \mathrm{~cm}$ intervals in a grid pattern, keep the soil much drier and carefully weed around the plants to allow air to their roots" (Vidal, 2013).

By leveraging this revolutionary crop intensification system, farmers end up using less water, seeds and chemicals. With no harmful impact on the environment and no additional investment required, cultivators in the Nalanda district region have been able to increase their yields up to $45 \%$ on average. Presently, it has been estimated that approximately 4-5 million farmers are utilizing SRI worldwide, with governments in China, India, Indonesia, Cambodia, Sri Lanka and Vietnam sponsoring it. In light of recent events, SRI has the potential to become what in the business environment is known as a "disruptive innovation" (Christensen, Baumann, Ruggles \& Sadtler, 2006; Schumpeter, 1942). As Uphoff (1999) also suggested, if SRI proves to be successfully scalable, industrial agricultural practices worldwide would likely have to be re-conceived and brought back to their biological roots. Over the last decades, agribusiness corporations have narrowly focused their efforts on enhancing crop yields by utilizing fertilizers and chemicals while guiltily forgetting about crops management. So did not farmers at the BoP, apparently.

The two cases presented here offer clear and convincing proof of the great potential impact GRI can have at the $\mathrm{BoP}$ in overcoming some of the world's most urgent needs. According to this view, traditional knowledge in indigenous settings can therefore represent the springboard for that type of innovation that has the potential of redirecting socioeconomic development towards a more sustainable and greener future for all of humanity (Figure 3).

Figure 3. A reinterpreted role of the $\mathrm{BoP}$

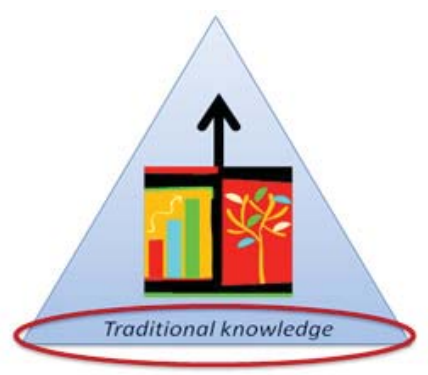

\section{Conclusions}

The old inclusive capitalism of "selling to the poor", without involving them in a value co-creation process, just ends with a temporary improvement of the poor conditions, but it keeps them at a perpetual dependence from the Western world. The 
main potential of the BoP is not so much represented by its purchasing power, but rather the embedded entrepreneurial spirit and capability. According to this logic, we consider the BoP a rich source of innovation and opportunity that needs to be nurtured rather than exploited.

Several cases of GRI at the BoP have recently captured the attention of the global community. The cases provided by the authors offer indeed clear evidence of the fact that rural practices in underdeveloped countries hold a latent potential to benefit the entire world and not just to solve local problems. For centuries, rural communities in Asia, Africa and South America have nurtured a kind of knowledge the western world seems to have lost due to the fostering of the kind of specialization that has progressively isolated biologists into separate camps - experts on soil structure versus plant nutrition - causing disastrous effects for the humus, critical ingredient of the nitrogen cycle. The natural tendency of the modern society (and therefore MNCs) to think of only one thing at a time is a chief reason why we have failed to understand the environment on countless occasions and are on the brink of destroying it.

As in the case of agribusiness, the same principles of identifying traditional knowledge and applying it on a large scale - in place of existing harmful business practices - can be valid for many other industries. This has to be empirically further explored. A second consideration that we hope will lead to future research is related to the acknowledgment that everything on Earth (and beyond) is interconnected. Keeping things simple, the four geochemical cycles critical for life nitrogen, water, carbon, and oxygen - are governed by the laws of nature according to which "everything is connected to everything else" and "everything must go somewhere". As a result of these assertions, what happens at the BoP will eventually impact the way of life of those in developed countries and vice versa, hence we can no longer think of us' and 'them'; a new understanding of 'globalization' needs to emerge and be recognized by society at large.

\section{References}

Bartlett, C., \& Goshal, S. (1989). Managing Across Borders. Harvard Business School Press, Boston, MA.

Brabham, D. C. (2008). "Crowdsourcing as a Model for Problem Solving, An Introduction and cases", Convergence: The International Journal of Research into New Media Technologies, Sage Publications, Vol. 14 (1): 75-90.

Chaurey, A., Krithika, P.R., Palit, D., Rakesh, S., \& Sovacool, B.K., (2012). New partnerships and business models for facilitating energy access. Energy Policy, 47, 48-55.

Christensen, C.M., Baumann, H., Ruggles, R., \& Sadtler, T.M. (2006). Disruptive innovation for social change. Harvard Business Review, 84(12), 94.

Ecovadis, (2012). Leading the way: UN Global Compact Participants and CSR performance. An Ecovadis study - 2012. Retrieved May 05, 2013, from http://www.ecovadis-survey.com/surveys/ EcoVadis\%202011\%20UN\%20Global\%20Compact\%20study.pdf

Davidson, K. (2009). Ethical concerns at the Bottom of the Pyramid: where CSR meets BoP. Journal of International Business Ethics, 2 (1), 22-32.

Fafchamps, M., \& Minten, B. (2012). Impact of SMS-Based Agricultural Information on Indian Farmers. The World Bank Economic Review, 26(3), 383-414.

Gottlieb, S. (2000). Companies reduce prices for HIV drugs in developing countries. Bull World Health Organization, 78(6), 862.

Hargreaves, T., Longhurst, N., \& Seyfang, G. (2013). Up, down, round and round: connecting regimes and practices in innovation for sustainability. Environment and Planning A 2013, 45, $402-420$.

Hart, S. L., \& Sharma, S. (2004). Engaging fringe stakeholders for competitive imagination. The Academy of Management Executive (1993-2005), 7-18.

Hertsgaard, M. (2009, December 7). Reegrening Africa. The Nation. Retrieved from http://www.thenation.com/article/ regreening-africa

Howe, J. (2008) Crowdsourcing. Why the Power Of the Crowd Is Driving the Future of Business, New York: McGraw-Hill.

ICRIER, (2009). "India: The impact of mobile phones" (The Policy Paper Series, Number 9). Retrieved May 02, 2013, from http://www.icrier.org/pdf/public_policy19jan09.pdf

Kubzansky, M., Cooper, A., \& Barbary, V. (2011). Promise and Progress: market-based solutions to poverty in Africa. Retrieved June 01, 2013, from web.mit.edu/idi/idi/Africa-\%20PromiseAndProgress-MIM.pdf

London, T. (2008). The Base-of-the-Pyramid Perspective: A New Approach to Poverty Alleviation. In Academy of Management Proceedings (Vol. 2008, No.1, pp. 1-6). Academy of Management.

London, T., \& Hart, S.L. (2004). Reinventing strategies for emerging markets: beyond the transnational model. Journal of international business studies, 35(5), 350-370.

Prahalad, C.K. (2004). The fortune at the bottom of the pyramid: eradicating poverty through profits. Wharton School Publishing, Philadelphia.

Prahalad, C.K., \& Ramaswamy, V. (2000). Co-opting customer competence. Harvard Business Review, 78(2), 189-190.

Prahalad, C.K., \& Ramaswamy, V. (2004). Co-creation experiences: The next practice in value creation. Journal of interactive marketing, 18(3), 5-14.

Reii, C., \& Waters-Bayer, A. (2001). Farmer innovation in Africa: a source of inspiration for agricultural development. Earthscan.

Sawa World, (2013). What we do. Retrieved June 20, 2013, from http://www.sawaworld.org/what-we-do 
Schumpeter, J.A. (1942). Capitalism, Socialism and Democracy. New York: George Allen \& Unwin.

Seyfang, G., \& Haxeltine A. (2012). Growing grassroots innovations: exploring the role of community-based initiatives in governing sustainable energy transitions. Environment and Planning C: Government and Policy 2012, 30, 381-400.

Seyfang, G., \& Longhurst, N. (2012). Grassroots innovation sustainability: a niche analysis of community currencies. Science, society \& sustainability, Working Paper 2012-10.

Seyfang, G., \& Smith A., (2007). Grassroots innovations for sustainable development: Towards a new research and policy agenda. Environmental Politics, 16(4), 584-603.

Simanis, E., \& Hart, S. (2006). Expanding Possibilities at the Base of the Pyramid. Innovations: Technology, Governance, Globalization, $1(1), 43-51$.

Simanis, E., \& Hart, S. (2008). The Base of the Pyramid Protocol: Toward Next Generation BoP Strategy. Working Document, Cornell University.

Smith, A. (2007). Translating Sustainabilities between Green Niches and Socio-Technical Regimes. Technology Analysis \& Strategic Management, 19(4), 427-450.

Sovacool, B. (2013). Expanding renewable energy access with pro-poor public private partnerships in developing world. Energy Strategy Reviews, 1(3), 181-192.

Toffler, A. (1980), The Third Wave. NY: Bantam Books.

United Nation ESCAP, (2010). Lighting up Lives: Pro-Poor Public Private Partnerships (Energy Component, Indonesia). Retrieved May 10, 2013, from http://www.unescap.org/esd/Energy-Security-and-Water-Resources/energy/cap_building/ppp/

Uphoff, N. (1999). Agroecological Implications of the System of Rice Intensification (SRI) in Madagascar. Environment, Development and Sustainability, 1(3-4), 297-313.

Vidal, J. (2013, February 16). India's rice revolution. The Guardian. Retrieved from http://www.guardian.co.uk/globaldevelopment/2013/feb/16/india-rice-farmers-revolution

Yara International, (2013). Agricultural Growth Corridors. Retrieved June 05, 2013, from http://www.yara.com/sustainability /how_we_engage/africa_engagement/growth_corridors/index.aspx 